\title{
Experiences and opinions of health professionals in relation to the presence of the family during in-hospital cardiopulmonary resuscitation: An integrative review
}

\author{
Ana Paula Fernandes ${ }^{1}$, Camila de Souza Carneiro², Luciana Geocze ${ }^{2}$, Vinícius Batista Santos ${ }^{2}$, \\ Solange Guizilini ${ }^{1}$, Rita Simone Lopes Moreira ${ }^{2}$ \\ 1. Universidade Federal de São Paulo, São Paulo, Brazil. 2. São Paulo Hospital, São Paulo, Brazil.
}

\begin{abstract}
Correspondence: Ana Paula Fernandes. Address: Universidade Federal de São Paulo (UNIFESP), São Paulo, SP, Brazil. Email: anapaulamacaubal@hotmail.com
\end{abstract}

Received: April 17, 2013

DOI : $10.5430 /$ jnep.v4n5p85
Accepted: February 12, $2014 \quad$ Online Published: March 13, 2014

URL: http://dx.doi.org/10.5430/jnep.v4n5p85

\begin{abstract}
The presence of the family during cardiorespiratory resuscitation efforts has been reported for more than twenty years and, despite a lack of strong evidence of its benefit, the tendency to not permit this practice has been observed. The aim of this review is to identify studies in the global literature performed about the experiences and opinions of nurses and other health professionals regarding the presence of the family during intra hospital cardiorespiratory arrest. An integrative review according to steps suggested by $\mathrm{G}$ among was conducted that enabled the identification of four hundred and one articles, of which fourteen were selected. These are indexed in LILACS, IBECS and MEDLINE databases, using the keywords "family," "cardiorespiratory arrest," "cardiopulmonary resuscitation" and "health professionals". The analyses unit used was the theme and the categorizations were given by: health professionals experiences and opinions relationship aspect regarding the presence of the family during the cardiorespiratory arrest attendance. In $57.1 \%$ of the selected studies, the professionals responding experienced a call to cardiopulmonary resuscitation (CPR) with family presence on site. Only two articles (14.2\%) reported that professionals were in favor of family presence during CPR, while 57.1\% were against this practice; among these were most professionals from Asian countries. It was concluded that the majority of studies are against the presence of the family during cardiorespiratory arrest although there is a trend to implement this practice, the majority of professionals are not supportive, at the same time, they coexist with the practice. Thus, research in every continents that exploring the experiences and attitudes of family members, nurses and other health professionals can broaden the understanding on the subject, as well as provide best health polices practices available for implementation in all attendance services.
\end{abstract}

\section{Key words}

Family, Cardiopulmonary resuscitation, Cardiopulmonary arrest, Healthcare professional

\section{I ntroduction}

Cardiopulmonary arrest is a stressful and critical event for families and healthcare professionals. The presence of family members during this and other emergencies has been debated since the early $1980 \mathrm{~s}^{[1]}$, with it becoming a common practice in many hospitals in the world, mostly American; it has been well documented in the literature ${ }^{[2]}$. 
The presence of the family (PF) in resuscitation, or witnessed resuscitation, is defined as one or more family members in the care area that provides physical or visual contact with the patient during the process of cardiopulmonary resuscitation, including witnessing of all interventions performed for the patient ${ }^{[3,4]}$.

Over the last 25 years, there was a tendency to promote a caring environment focused on family-centered care ${ }^{[5]}$. Despite having the right to be present at the bedside of loved ones during care, invasive procedures and even CPR, only $5 \%$ of intensive care units in the United States have written policies permitting family presence during cardiopulmonary resuscitation (CPR) ${ }^{[6]}$. This could suggest that a lack of studies describing the effects of family presence during cardiopulmonary resuscitation feeds the controversy with respect to the subject, and slows the creation of policies that endorse this issue. Or that while evidence exists which supports such a policy, the implementation of research into practice settings lags due to a lack of support by health care personnel.

The review of studies ${ }^{[7,8]}$ found a range from case reports to the creation of institutional protocols ${ }^{[5,9]}$. Many studies report questionnaires involving professionals that attend to such emergencies and their respective views about the presence of family members during cardiopulmonary resuscitation, and differences of experience among them in different countries ${ }^{[10-17]}$. Discrepancies were found regarding the subject matter range from the opinions of different professional categories through those among professionals in different countries ${ }^{[10,14]}$. Some studies suggest that the nurses have a more favorable opinion toward the practice than the medical team ${ }^{[2,7,10]}$, while others demonstrate that Asian professionals ${ }^{[1,11,15,18]}$ are more resistant than Westerners ${ }^{[16,19]}$. A number of studies conducted in Germany and Norway ${ }^{[12,14,20]}$ were supportive of family presence during emergencies.

The literature seems to suggest a growing trend towards the acceptance of family presence during CPR in the hospital environment, because its facilities the communication between health professionals and family members providing by this way the dead and mourning acceptance ${ }^{[4,5,16,19]}$. However, there is evidence to suggest that, without formal written policies, a continued resistance to permitting families to remain with their family member during CPR exists ${ }^{[5]}$. Allowing family presence during resuscitation has been proposed as a way to better support the emotional needs of family members and to facilitate improved decision-making. Hence, research exploring the experiences and attitudes of nurses and other health professionals can broaden the understanding on the subject as well as provide the best available practices for implementation of policies favorable to this practice, and to understand more clearly the potential implications of adoption of such policies ${ }^{[5]}$.

\section{Objective}

To identify studies in the literature conducted about the experiences and opinions of nurses and other health professionals regarding the presence of the family during intrahospital cardiopulmonary arrest.

\section{Methods}

This was an integrative review of the literature, based on the steps proposed by Ganong ${ }^{[21]}$ which are as follows:

\subsection{Selection of the hypotheses or questions for review}

The study was designed to answer the following question: "What are the opinions and experiences of health professionals about family participation during in-hospital cardiopulmonary resuscitation?"

\subsection{Criteria for selection of the sample}

Articles selected were indexed in LILACS, IBECS and MEDLINE using the keywords "family", "cardiac arrest", "CPR" and "health professionals", with the following filters: ("family" [MeSH Terms] OR "family" [All Fields]) AND ("heart arrest" [MeSH Terms] OR ("heart" [All Fields] AND "arrest" [All Fields]) OR "heart arrest" [All Fields] OR ("cardiac" [All Fields] AND "arrest" [All Fields]) OR "cardiac arrest" [All Fields]) AND ("cardiopulmonary resuscitation" [MeSH Terms] OR ("cardiopulmonary" [All Fields ] AND "resuscitation" [All Fields]) OR "cardiopulmonary resuscitation" [All 
Fields]) AND ("health personnel" [MeSH Terms] OR ("health" [All Fields] AND "personnel" [All Fields]) OR "health personnel "[All Fields] OR (" health" [All Fields] AND "professional" [All Fields]) OR "health professional" [All Fields]) AND ((English [lang] OR Spanish [lang] OR Portuguese [lang]) AND medline [sb] AND "adult" [MeSH Terms] AND "09/14/2006" [PDat]: "09.12.2011" [PDat]).

The search for articles occurred from March 2011 to September 2011. The review covered the period from 2006 to 2011, in order to combine the latest research on the subject. Articles published in Portuguese, English and Spanish were included that described the experiences and opinions of nurses and other health professionals about the presence of family during care provided for cardiac arrest. The articles were included in the sample following an analysis of titles and abstracts.

Based on the criteria, we excluded studies that did not address the chosen theme, such as: articles dealing with cardiopulmonary arrest in children, in terminally ill patients who were not resuscitated, those that reported the opinions of the patients, those that dealt with CPR outside the hospital, among others.

We initially selected 401 articles, of which 14 met all of the inclusion criteria. The articles included in the sample were read in their entirety, and their contents were analyzed according to the technique described by Sampieri ${ }^{[22]}$, which consists of evaluating each study starting from one unit of analysis (subject, item, character and time-space) and from there, categorizing the studies, grouping them according to the data found in each one. The unit of analysis used for this study was the theme, and following this, studies were categorized according to the aspects related to the experiences and opinions of the health professionals regarding family presence during the cardiorespiratory arrest care.

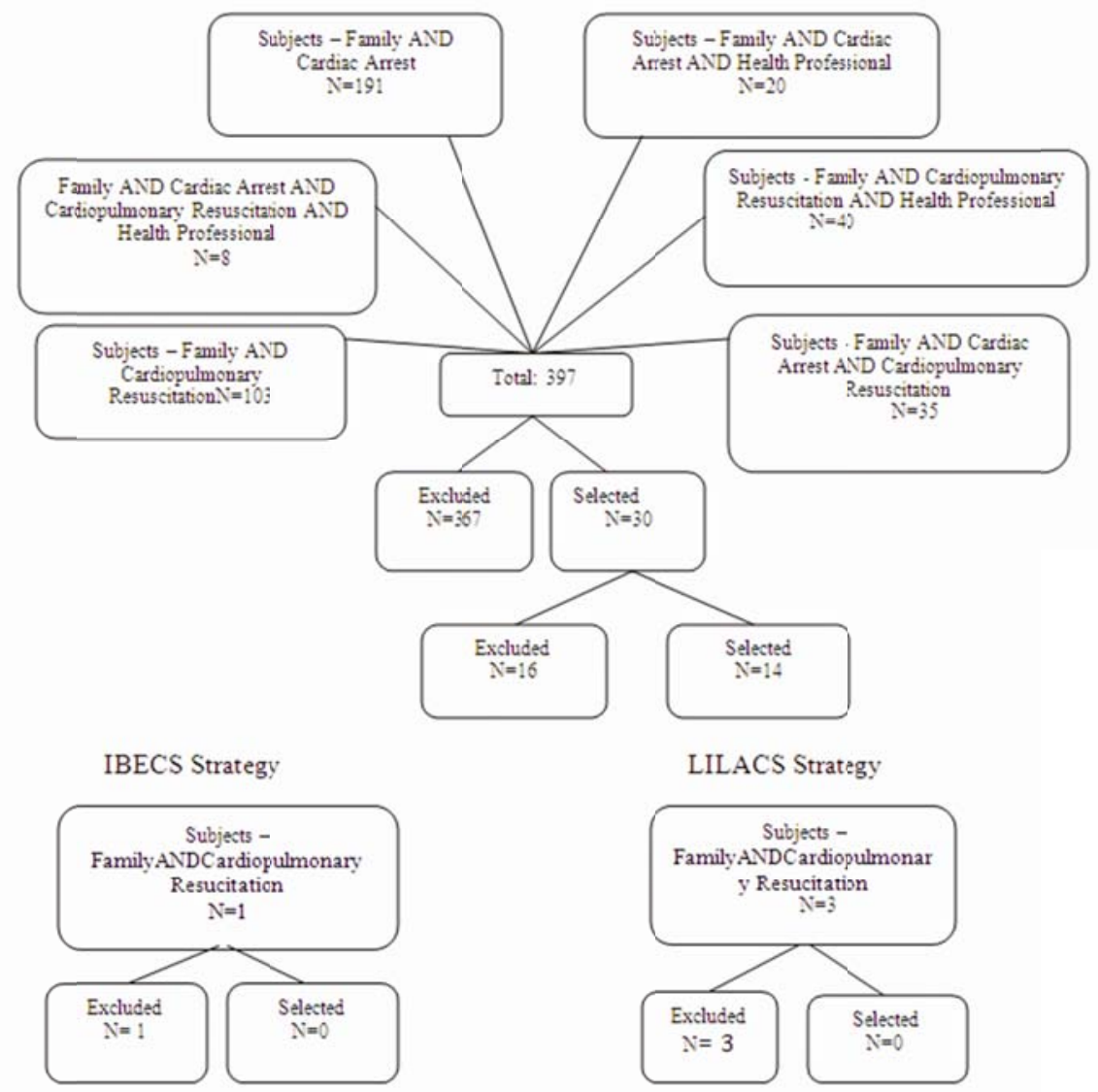

Figure 1. Finding and selecting the data

The characteristics of the primary research will be presented, based on the analysis of the fourteen selected articles. The information obtained was recorded in the following manner: article title, reference number, year, objective, method, use of 
instruments to assess the experiences and opinions of professionals about the theme, which professionals were the target of the investigations, the country in which the study was conducted, and the experiences and opinions of the health professionals about this practice.

Regarding the authorship of the fourteen articles analyzed, nine were written by nurses (64.2\%), four were authored by physicians (28.5\%), and one study (7.1\%) included physicians and nurses. The articles were published in: 2010 (five, 35.7\%); 2009 (one, 7.1\%); 2008 (four, 28.5\%); and, 2007 (four, 28.7\%). The vast majority of articles (nine, 64.2\%) were published in nursing journals. The approach of those articles in our literature review included: nine (64.2\%) were descriptive quantitative; three (21.4\%) were descriptive qualitative; and, two were quantitative (14.2\%). With regard to the design utilized, twelve (85.7\%) were of the transversal type.

Regarding the country in which the studies were performed, five (35.7\%) were conducted in eastern countries (Turkey, Pakistan, Iran) and nine (64.2\%) in western countries (USA, UK, Ireland, Israel, Germany, Norway, Sweden and Canada).With respect to the questionnaires used, five (35.7\%) created their own questionnaire, while seven (42.8\%) were based on pre-existing questionnaires. The vast majority of the studies included in this sample were conducted in university hospitals (8\% - 57.1\%), while two (14.2\%) were performed during congresses, one (7.1\%) at a military hospital, and one (7.1\%) by sending questionnaires via e-mail.

Based on the analysis of the content, it was possible to identify and categorize the studies according to the opinion of the health professionals in relation to the presence of the family during CPR. The content covered in the articles was categorized based on previous experiences and opinions with respect to the presence of the family during CPR (see Table 1). Regarding the target sample of the research, in six of the articles (42.8\%) the professionals interviewed were nurses, in five (35.7\%) they were physicians and nurses, in one (7.1\%) they were surgeons, and in two $(14.2 \%)$ all of the health professionals were included.

Table 1. Description of the articles included in the study

\begin{tabular}{|c|c|c|c|c|c|c|c|}
\hline Title & Year & Purpose & Methods ${ }^{*}$ & Instrument & Target group & Country & Opinions and experiences \\
\hline $\begin{array}{l}\text { The attitudes of team } \\
\text { members toward } \\
\text { family-based hospital } \\
\text { rresence during CPR: a } \\
\text { study based in the Iranian } \\
\text { Muslim setting of four } \\
\text { teaching hospitals. }\end{array}$ & 2010 & $\begin{array}{l}\text { To determine the } \\
\text { opinion of health } \\
\text { professionals } \\
\text { based on a } \\
\text { Muslim } \\
\text { definition about } \\
\text { family presence } \\
\text { during CPR. }\end{array}$ & DCS, QTS & SSQ & $\begin{array}{l}\text { Physicians and } \\
\text { nurses }\end{array}$ & Iran & $\begin{array}{l}\text { Experiences: } 82 \% \text { of the physicians and } 69 \% \text { of the nurses } \\
\text { had a previous experience with the presence of family } \\
\text { during CPR } \\
\text { Opinions: A large majority opposed to the presence of the } \\
\text { family during CPR believed that the presence of the family } \\
\text { increased stress and affected the performance of the team, } \\
\text { could prolong the time of resuscitation, causing trauma to } \\
\text { the family and increasing judicial demands.. }\end{array}$ \\
\hline $\begin{array}{l}\text { Family witnessed } \\
\text { resuscitation - experience } \\
\text { and attitudes of German } \\
\text { intensive care nurses. }{ }^{12 \mathrm{th}}\end{array}$ & 2010 & $\begin{array}{l}\text { Explore } \\
\text { experiences of } \\
\text { German intensive } \\
\text { care nurses and } \\
\text { their attitudes } \\
\text { towards } \\
\text { family-witnessed } \\
\text { CPR. }\end{array}$ & $\begin{array}{l}\text { QT,QL,DS, } \\
\text { CS }\end{array}$ & SQ & Nurses & Germany & $\begin{array}{l}\text { Experiences: } 42.2 \% \text { had experienced witnessed CPR with } \\
\text { the presence of family, and of these, } 65.7 \% \text { reported it as } \\
\text { having been negative. } \\
\text { Comments: } 67.5 \% \text { of the nurses who disagreed with the } \\
\text { presence of the family in witnessed CPR believed that } \\
\text { family presence may interfere and prolong the procedure, } \\
\text { affect the concentration of the team, cause distress to the } \\
\text { family. Space is limited, there are not enough professionals } \\
\text { to support the family and avoid breach of confidentiality. }\end{array}$ \\
\hline $\begin{array}{l}\text { Health care providers' } \\
\text { attitudes regarding family } \\
\text { presence during } \\
\text { resuscitation of adults: an } \\
\text { integrated review of the } \\
\text { literature. }{ }^{13 \text { th }}\end{array}$ & 2010 & $\begin{array}{l}\text { Discover the } \\
\text { attitudes of } \\
\text { health care } \\
\text { providers about } \\
\text { the resuscitation } \\
\text { of adults during } \\
\text { family presence. }\end{array}$ & SLR & RED & $\begin{array}{l}\text { Doctors and } \\
\text { nurses }\end{array}$ & $\begin{array}{l}\text { United } \\
\text { States. }\end{array}$ & $\begin{array}{l}\text { Experiences: not reported } \\
\text { Comments: There was not a pre dominance of opinion for } \\
\text { or against. Negative effects: increased psychological stress } \\
\text { and anxiety in the team, possible interference of the family, } \\
\text { increased litigation, insufficient or inadequate space, fear } \\
\text { of family noticing an error, violence towards staff. Positive } \\
\text { effects: it facilitates the grieving process, meets the } \\
\text { emotional and spiritual needs of the family and the feeling } \\
\text { that everything was done by the loved one. }\end{array}$ \\
\hline $\begin{array}{l}\text { Attitudes of emergency } \\
\text { department staff toward } \\
\text { family presence during } \\
\text { resuscitation. }{ }^{8 \text { th }}\end{array}$ & 2010 & $\begin{array}{l}\text { Examine the } \\
\text { attitudes of } \\
\text { physicians and } \\
\text { nurses regarding } \\
\text { the presence of } \\
\text { family members } \\
\text { during CPR. }\end{array}$ & $\begin{array}{l}\text { DS,QL,QT, } \\
\text { CS }\end{array}$ & SSQ & $\begin{array}{l}\text { Doctors, } \\
\text { nurses and } \\
\text { other health } \\
\text { professionals }\end{array}$ & Israel & $\begin{array}{l}\text { Experiences: not reported } \\
\text { Comments: most were against the presence of the family } \\
\text { during CPR. They believed that there would be greater } \\
\text { pressure on the team, fear of lawsuits and hurting the } \\
\text { feelings of the family, lack of space, loss of objectivity in } \\
\text { the procedure, insufficient staff to treat the family. }\end{array}$ \\
\hline
\end{tabular}


Table 1. Continued.

\begin{tabular}{|c|c|c|c|c|c|c|c|}
\hline Title & Year & Purpose & Methods* & Instrument & Target group & Country & Opinions and experiences \\
\hline $\begin{array}{l}\text { A study of Turkish } \\
\text { critical care nurses' } \\
\text { perspectives } \\
\text { regarding } \\
\frac{\text { family-witnessed }}{\text { resuscitation. }^{\text {th }}}\end{array}$ & 2009 & $\begin{array}{l}\text { To determine the } \\
\text { experiences and } \\
\text { attitudes of Turkish } \\
\text { nurses' criticism about } \\
\text { family presence during } \\
\text { CPR. }\end{array}$ & DS,QT,CS & SQ & Nurses & Turkey & $\begin{array}{l}\text { Experiences: } 22 \% \text { had experienced CPR with family } \\
\text { presence. } 33.3 \% \text { had one or more positive } \\
\text { experiences and } 66.7 \% \text { negative. } \\
\text { Comments: } 91.1 \% \text { of nurses opposed to the presence } \\
\text { of family during CPR believed that family presence } \\
\text { may increase stress and affect performance and team } \\
\text { performance, cause trauma for the family, increase } \\
\text { lawsuits, loss of confidentiality, prolong the } \\
\text { procedure, lead to interference, and lack of } \\
\text { professional staff to support the family. }\end{array}$ \\
\hline $\begin{array}{l}\text { Presence of family } \\
\text { members during } \\
\frac{\text { cardio-pulmonary }}{\text { resuscitation after }} \\
\text { necessary } \\
\text { amendments.15th }\end{array}$ & 2008 & $\begin{array}{l}\text { Discover the attitudes } \\
\text { of health professionals } \\
\text { and family members, to } \\
\text { testify on RCR. }\end{array}$ & QT,A,CS & SSQ & $\begin{array}{l}\text { Doctors, } \\
\text { nurses }\end{array}$ & Pakistan & $\begin{array}{l}\text { Experiences: None reported } \\
\text { Reviews: } 95 \% \text { of all doctors and nurses opposed to } \\
\text { the presence of the family during CPR believed that } \\
\text { family presence may traumatic experience for the } \\
\text { family, family can find flaws in attendance, assume } \\
\text { that the team is contributing to the patient's death and } \\
\text { interfere in the procedure, reduced space }\end{array}$ \\
\hline $\begin{array}{l}\text { Family presence } \\
\text { during } \\
\text { resuscitation: a } \\
\text { survey of Canadian } \\
\text { critical care nurses' } \\
\text { practices and } \\
\text { perceptions. }\end{array}$ & 2008 & $\begin{array}{l}\text { Identify the preferences } \\
\text { and practices of critical } \\
\text { care nurses Canadians } \\
\text { about the presence of } \\
\text { family members during } \\
\text { resuscitation as well as } \\
\text { the existence of formal } \\
\text { policies in hospitals. }\end{array}$ & DS,QT,CS & SSQ & Nurses & Canada & $\begin{array}{l}\text { Experiences: } 32.5 \% \text { report having taken the family } \\
\text { to witness the CPR. } \\
\text { Comments:The majority of respondents ( } 92 \%) \\
\text { supported the presence of the family during CPR in } \\
\text { intensive care. }\end{array}$ \\
\hline $\begin{array}{l}\text { Accident and } \\
\text { emergency staff } \\
\text { opinion on the } \\
\text { effects of family } \\
\text { presence during } \\
\text { adult resuscitation: } \\
\text { critical literature } \\
\text { review.17th }\end{array}$ & 2008 & $\begin{array}{l}\text { Identify the opinions of } \\
\text { emergency } \\
\text { professionals on the } \\
\text { effects of family } \\
\text { presence during } \\
\text { resuscitation of adults. }\end{array}$ & CRL & RED & $\begin{array}{l}\text { Health } \\
\text { Professionals }\end{array}$ & $\begin{array}{l}\text { UK, } \\
\text { USA, } \\
\text { Australia } \\
\text {, South } \\
\text { Africa, } \\
\text { Sweden, } \\
\text { Singapor } \\
\text { e and } \\
\text { Turkey }\end{array}$ & $\begin{array}{l}\text { Experience: More than half reported having } \\
\text { experience with family presence during CPR. } \\
\text { Comments: Most believed that there were more risks } \\
\text { than benefits in FP in CPR. Weaknesses: stress and } \\
\text { inhibition of team performance, legal repercussions, } \\
\text { claims by relatives, prolonged CPR, inadequate } \\
\text { space. Strengths: facilitates communication and } \\
\text { mourning, understanding and acceptance of death. }\end{array}$ \\
\hline
\end{tabular}

Presence of patients' families during cardiopulmonary resuscitation: physicians' and nurses' opinions. ${ }^{23}$
Determine the opinion of physicians andnurses working in an intensive care unit on the presence of the families of patients during CPR.
DS, QT,CS SSQ $\quad \begin{aligned} & \text { Physicians and } \\ & \text { nurses }\end{aligned} \quad$ Turkey

Experiences: $64.6 \%$ reported no experience with family presence during CPR and those who had reported it as being negative.

Comments: Large majority (82\%) of the professionals were against the FP during CPR because they believed the procedure was traumatic, there could be family interference and misinterpretation of the procedure, increasing pressure on the staff and judicial demand, reduced space, extension of CPR time.

Experiences: most had previous experiences with CPR.

Determine if previous demographic factors toward family experience and presence during resuscitation procedures.19th

Emergency nurses' current practices and understanding of family presence during CPR. ${ }^{\text {th }}$

Trauma surgeons' attitude towards family presence trauma during resuscitation: a nationwide survey.20th

Family presence during CPR: a study of the experiences and opinions of Turkish critical care nurses. $^{18 \text { th }}$ in relation to the presence of the RCR family.

Examining the 2007 nurses regarding the emergency care in Ireland.

Analyze the attitude of trauma surgeons toward the presence of family

Determine the experiences and 2007 opinions of Turkish an predict the attitudes of health professionals practices of emergency understanding of family presence during CPR in during CPR in trauma. DS,QT,CS SSQ

Physicians and United

$\begin{array}{lll}\text { DS,QT,CS SSQ } & \begin{array}{l}\text { Physicians and } \\ \text { nurses }\end{array} & \begin{array}{l}\text { United } \\ \text { States. }\end{array} \\ & & \\ & \end{array}$

Opinions: The majority favored FP during CPR, however, $45 \%$ believed that the FP could increase the stress on staff and $52 \%$ believed there may be difficulties in teaching students and residents during the procedure.

Experiences: $58.9 \%$ had taken the family to the bedside during CPR.

Reviews: $58 \%$ believed there may be conflict between the staff, $50 \%$ increased stress of the team, $39 \%$ feared lawsuits and $27 \%$ feared that the family could interfere in the procedure.

Experiences: $36.2 \%$ reported no experience with family presence during CPR. 56\% reported being positive and $19 \%$ negative.

Reviews: $50 \%$ opposed the presence of the family in trauma room during CPR due to the presence of blood, post-traumatic disorders, fear of judicial demand

Experiences: 63\% reported no experience with family presence during CPR, and those who had, most had negative experiences. QT,DS,CS SQ

Nurses

Turkey Comments: $69.1 \%$ opposed the presence of the family during CPR (stress for the family, little room, family interference, lack of professional support to the family, extend CPR, breach of confidentiality of the procedure)

Notes. $\mathrm{FP}=$ Family presence; $\mathrm{CPR}=$ cardiopulmonary resuscitation

*QT- Quantitative Study, QL- Qualitative, Study, DS- Descriptive Study, CS- Cross Sectional, CRL- - Critical Literature Review, SLR- Systematic Literature Review, A- Anallytical

** - SSQ - Semi- structured questionnaire, SQ- Structured questionnaire, RED - Research on electronic database 


\section{Categorization of results}

\subsection{Experiences and opinions}

In the majority of the texts (eight, $57.1 \%$ ) the responding professionals had already been called to a CPR event with family presence on site. Some studies related previous experiences of FP during CPR with a greater acceptance of the practice $^{[13,17,19,20]}$ and vice versa ${ }^{1}$ while others found no such relationship ${ }^{[8,11,16]}$. The inclusion of these concepts for the undergraduate courses of nursing and medicine were quoted in two of the sample articles ${ }^{[15,19]}$. Among the fourteen selected studies, only two (14.2\%) reported that professionals were in favor of family presence during CPR, while eight (57.1\%) were against this practice. Those articles against the practice had the the vast majority (7\%- 87.5\%) with professionals from Eastern countries.

\subsection{Factors that hinder the practice}

Some factors were cited in most studies as a justification for disagreement regarding the presence of the family during CPR, including: the possible increase in stress ${ }^{[1,6,8,11,13,17,18,23]}$ and misunderstanding of the team ${ }^{[6,12,14]}$ decreased concentration and performance of the team ${ }^{[11,13,17]}$, prolonging the resuscitation time ${ }^{[11,12,14,17,18,23]}$, psychological trauma $^{[1,11,13,15,20]}$ and distress ${ }^{[12,14]}$ for the family, interference ${ }^{[6,12,15,23,18]}$ or complaints ${ }^{[17]}$ from the family during the procedure, reduced $^{[8,12,15,18,23]}$ or inadequate ${ }^{[13,17,20]}$ space, increase in lawsuits ${ }^{[1,6,8,11-13,17,20,23]}$ and, lack of professionals to provide support to the family ${ }^{[8,12,14,18]}$. Other less commonly cited factors include: difficulty in teaching students and residents in teaching hospitals ${ }^{[19]}$, erroneous interpretation ${ }^{[13,23]}$ or faults identified during the procedure ${ }^{[15]}$, and breach of confidentiality about these issues ${ }^{[18]}$.

\subsection{Factors that facilitate the practice}

In contrast, in the other articles that related opinions in favor of this practice, some items stood out as positives: the strengthening of family bonds, facilitation of grieving, avoiding distorted images of care ${ }^{[13,14]}$, facilitating communication, understanding and acceptance of death, certainty that everything was done, and giving their loved one the opportunity to share in the last moment ${ }^{[13,17]}$. Even in articles with a strong tendency not to accept this practice, professionals have reported that the presence of the family during CPR may make it easier for the family to accept the death, which is their right, and that there is increased confidence in the team and that it improved professional behavior ${ }^{[23]}$.

\subsection{Difference of opinion between professional categories}

Regarding the professional category, we found a tendency on the part of nurses to favor family participation during CPR compared with the medical staff ${ }^{[8,13,15,17]}$. In some studies we found reports that nurses in bedside care were less in favor than those who occupied positions of management and research ${ }^{[14]}$.

A German study compared the opinion of female versus male surgeons in relation to the presence of the family during CPR. In it, women (44\%) were more informed than men (37.2\%) on the topic and they also did not believe that the team would have more errors, or that an increase in lawsuits would occur. Another important aspect reported in that same study was that the chiefs knew less than the residents about the subject, although they thought the question was most relevant ${ }^{[20]}$.

\subsection{Difference of opinion between countries}

Some studies compared the difference between countries, for example, a study conducted at a conference in Europe investigated the views of professionals from various countries, such as Norway, Ireland, the United Kingdom and Sweden. In this study, the difference of experience was reflected in acceptance or not of the practice, as noted in the Norwegian nurses, who had less contact with this practice and who were also less in favor of it ${ }^{[14]}$. Another study conducted in Canada also identified a trend in favor of the practice by Canadian nurses in relation to those from the USA ${ }^{[16]}$. 


\subsection{Adequate professionals}

The necessity of an exclusive professional to give support to the family was identified in some studies in the sample ${ }^{[8,12-14,17]}$. The relevant aspects concerning the lack of sufficient and adequate professionals in the majority of places to perform this role ${ }^{[1,17]}$, as well as the inclusion of the multidisciplinary team (physicians, nurses, social workers and psychologists) ${ }^{[6,8,13]}$ especially the social work professional ${ }^{[15]}$.

\subsection{Institutional protocols and guidelines}

The absence of pre-existing protocols in the workplaces of the interviewees was a constant in the sample, where five of the selected studies (35.7\%) reported not having family presence protocols or policies during CPR in their workplace. Only three studies confirmed policies in their place of work: $6 \%$ of professionals in Germany ${ }^{[12]}, 12 \%$ in the United Kingdom $^{[14]}$, and $8 \%$ in Canada ${ }^{[16]}$.

\subsection{Who should make the decision?}

With respect to which person should have the decision-making authority in the European study, 74\% believed the decision should be made by the staff, and $60 \%$ did not agree with a joint decision with the family ${ }^{[14]}$. Already in two Turkish studies ${ }^{[14]}, 80 \%$ in one ${ }^{[1]}$ and $47.2 \%$ in the other ${ }^{[23]}$, believed the decision should be made as a team ${ }^{[1]}, 42.9 \%$ and $20.8 \%$ by physicians ${ }^{[23]}, 19.3 \%$ by nurses ${ }^{[1]}, 26.4 \%$ by physicians and nurses ${ }^{[23]}$, and $90.3 \%$ believed that the family should not be included in the decision-making, whereas $2.7 \%{ }^{[23]}$ believed the family must participate.

\subsection{Cultural variations}

Cultural variations were reported in four (28.5\%) of the studies as an important factor in the acceptance of the practice, in relation to the sight of death and lack of experience and education on the subject, as well as differences in the health systems of each country ${ }^{[1,17]}$.

\subsection{Education and training}

Regarding aspects on continuing education, training and professional policies, the creation of new research and educational programs on the subject were cited in $100 \%$ of studies, demonstrating the need to expand and enhance the view about this practice. Research with pilot projects ${ }^{[15]}$, including the opinion of the family ${ }^{[23]}$, qualitative studies ${ }^{[17]}$, simulations ${ }^{[13,19]}$, national campaigns ${ }^{[12]}$, and insertion of politics ${ }^{14}$ and the media ${ }^{6}$ were some of the initiatives cited by the selected studies.

\section{Discussion}

After the analysis and interpretation of research data and the primary categorization of the articles, it was possible to synthesize and discuss the data found in the studies. Family presence during invasive procedures and CPR is a controversial subject, an ethical dilemma, and contributes to conflicting opinions among health professionals that attend to this emergency. However, movements in favor of this practice are increasing due to new research that has been conducted and the requests of family members that, increasingly, are aware of their rights ${ }^{[6]}$.

Twenty-five years ago the practice was instituted for the first time, a formal written policy endorsing the practice of the presence of the family at the bedside during cardiopulmonary resuscitation, at Foote Hospital in Jackson, Michigan (USA) ${ }^{[5]}$. This event occurred in 1982 and led the hospital to develop a formal policy allowing families to remain at the bedside during $\mathrm{CPR}$, in certain cases ${ }^{[5]}$. Currently, studies point to the establishment of protocols and policies so that professionals can exercise this practice with more security and legal support. For example, a study in Ireland showed that $74 \%$ of nurses preferred to have a written policy regarding family presence in their workplace ${ }^{[6]}$. Other studies also suggest that this practice, along with protecting the professional, protects the patient ${ }^{[20]}$. In 2000, the American Heart 
Association, started recommending that permission to be present during resuscitation attempts should be given to all of the family members ${ }^{[14]}$. This study identified a contradiction, in that most studies showed that while professionals live with this practice, they are not in favor of it or the way in which it has been implemented. This can be demonstrated by the high rate of professionals who had already attended a cardiac arrest witnessed by family ${ }^{[6,11,17-19,23]}$ and who still believed that the practice was not feasible for the reasons already explained ${ }^{[1,11,12,14,15,18,23]}$.

The difference of opinions and experiences of professionals between eastern and western countries was relevant in this study, in that it showed that cultural differences and different healthcare systems can influence professional practice. For example, Israeli, Turkish, Iranian and Pakistani professionals ${ }^{[1,10,11,15,18]}$ overwhelmingly opposed the presence of the family during CPR, when compared to professionals from Canada, the USA, Ireland and Germany ${ }^{[6,16,19,20]}$.

The selected articles were also able to reaffirm the opinion of the professionals of the same country, such as Turkey in three studies, one in $2010^{[1]}$, one in $2008^{[16]}$ and another in $2007^{[20]}$, which confirmed the rejection of that practice by the nurses in that country with a percentage against the practice of $91.1 \%$, 82\%and $69.1 \%$, respectively. The three studies indicated a lack of familiarity with and information about the practice by the nurses, and also highlighted the importance of professional education regarding this matter, since the practice has been widely accepted in the Turkish health system, which in turn is undergoing several changes due to globalization.

In contrast, Germany has demonstrated a difference in relation to the views of its staff since a study in 2010 [10] demonstrated a rejection rate of the practice among nurses of $67.5 \%$, and in another, in $2007^{[19]}$, by $50 \%$ of surgeons. However, this difference might be explained by the fact that the professionals targeted by the research were from different professional categories and act in different areas of health care.

Moreover, we observed a strong trend of family presence during CPR, taking into consideration the holistic model of care. This can be demonstrated by the tendency of the family to want to be with their loved ones during critical hours, including CPR. In two studies jointly addressing the opinion of professionals and family members, when questioned, 94\% and $35.4 \%$ expressed interest in being present during $\mathrm{CPR}^{[15,23]}$. This raises an important issue in that the majority of studies take into account the views of professionals, whereas the minority of these consider the opinions of family members. This led us to reflect on the question, to what extent do professionals have sufficient rights to give their opinions, and to underestimate the opinion of the family?

Despite the tendency of family presence at resuscitation, studies have failed to capture the impact of the traditions, values and cultures of different countries regarding this practice ${ }^{[1,15,17,23]}$. Most studies recommend more research that includes countries from South America, Central America, Australia, India, Indonesia, much of them with specific cultural characteristic on the subject in order to address cultural variations, different health systems, and a more thorough investigation of the matter to analyze the views of patients and family, and the social, cultural, ethical and legal aspects, once a time that this study isn't found anyone work in respect to this issue in this places ${ }^{[1,8,13,15,20]}$. Some studies suggest pilot studies to assess the availability, emotional adequacy, desire and family preparation, and to study strategies of emotional support after the event ${ }^{[15]}$. An important aspect ${ }^{[15,18]}$, already identified in the literature, is to also evaluate this issue by conducting more qualitative research on the subject.

The presence of a policy or guidelines was shown to be important in this context because it offered more security and legal support to the professional ${ }^{[13]}$. Some studies showed that no institutional protocol or written policy existed in hospitals ${ }^{[1,6,11,15,18,23]}$, or when they existed, they were in the minority ${ }^{[12,14,16]}$.

The ways to obtain changes in the opinions of the professionals should be focused on training, programs and educational initiatives ${ }^{[1,6,8,13-18,20]}$. The power of the media can help with programs and can help in raising awareness about the topic ${ }^{[6,15]}$ and to explain to the public the reality, since the survival rate after CPR is low. Moreover, the approach of concepts regarding family presence during CPR in professional education was also cited as a possible factor that was 
correlated with a greater acceptance of the practice ${ }^{[15,19]}$. This includes the need for these programs within Brazil, since no work on the subject was found that was conducted in the country.

\section{Study limitations}

The present study has some limitations, among which we highlight the fact that most studies were performed in a university hospital, which prevents us from understanding the reality of other hospitals, addressing the opinion of many professionals (physicians, nurses) from different areas (emergency, intensive care, surgery, cardiology). Moreover, studies in which professionals were more in favor were performed prior to the design proposed by the study, which reflected a more negative trend in practice.

\section{Conclusion}

The presence of the family during CPR is a complex issue whose acceptance is influenced by several factors in the daily practice of professionals around the world. This study showed a strong tendency for these professionals not to accept the practice, mainly within Eastern countries, although they considered it to be an important theme. As it showed that the majority of studies are against the presence of the family during cardiorespiratory arrest and the minority of the reported professionals had been this experience, more research is needed in order to raise awareness and introduce the professional to that practice. This has been shown that this study can be a method of achieving changes in attitudes and behaviors in relation to the presence of the family during the cardiorespiratory arrest regarding the acceptance of the dead and mourning. Furthermore, the implementation of policies to guide and legally protect professionals and elaborate grounded institutional protocols and the humanized care between family members and patients was shown to be necessary for greater acceptance and implementation of the practice with the objective to standardize them, as future expectations regarding the presence of family in the context health-illness are increasingly more intertwined.

\section{References}

[1] Gunes UY, Zaybac A. A study of Turkish critical care nurses' perspectives regarding family witnessed resuscitation. Journal of Clinical Nursing. 2009; 18(20): 2907-2915. PMid:19686324 http://dx.doi.org/10.1111/j.1365-2702.2009.02826.x

[2] Oman KS, Duran CR. Health Care Providers' evaluations of Family Presence During Resuscitation. Emerg Nurs. 2010; 36(6): 524-33. PMid:21078463 http://dx.doi.org/10.1016/j.jen.2010.06.014

[3] Boyd R. Witnessed resuscitation by relatives. Resuscitation. 2000; 43(3): 171-176. http://dx.doi.org/10.1016/S0300-9572(99)00147-1

[4] Bradley C; Lensky M; Brasel K.Family presence during resuscitation \#232. J Palliat Med. 2011; 14(1): 97-8. PMid:21244260 http://dx.doi.org/10.1089/jpm.2010.9743

[5] Doolin CT; Quinn LD; Bryant LG; Lyons AA; Kleinpell RM. Family presence during cardiopulmonary resuscitation: using evidence-based knowledge to guide the advanced practice nurse in developing formal policy and practice guidelines. J Am Acad Nurse Pract. 2011; 23(1): 8-14. PMid:21208329 http://dx.doi.org/10.1111/j.1745-7599.2010.00569.x

[6] Madden E, Condon C. Emergency nurses' current practices and understanding of family presence during CPR. Journal of Emergency Nursing. 2007; 33(5): 433-40. PMid:17884472 http://dx.doi.org/10.1016/j.jen.2007.06.024

[7] Hill R, Fuhrman C. Presence of family during resuscitation. Annals of Emergency Medicine. 2008; 52(3): 309-10. PMid:18722254 http://dx.doi.org/10.1016/j.annemergmed.2008.03.025

[8] Ott BB, McKay MA. A 7-year-old child witnesses CPR. J Emerg Nurs. 2011; 37(1): 100-1. PMid:21237380 http://dx.doi.org/10.1016/j.jen.2010.04.009

[9] Bradley C, Lensky M, Brasel K. Implementation of a family presence during resuscitation protocol \#233. J Palliat Med. 2011; 14(1): 98-9. PMid:21244261 http://dx.doi.org/10.1089/jpm.2010.9742

[10] Wacht O, Dopelt K, Snir Y, Davidovitch N. Attitudes of emergency department staff toward family presence during resuscitation. Isr Med Assoc J. 2010; 12(6): 366-70. PMid:20928992 
[11] Kianmehr N, Mofidi M, Rahmani H, Shahin Y. The attitudes of team members towards family presence during hospital-based CPR: a study based in the Muslim setting of four Iranian teaching hospitals. J R Coll Physicians Edinb. 2010; 40(1): 4-8. PMid:21125031 http://dx.doi.org/10.4997/JRCPE.2010.102

[12] Koberich S, Kaltwasser A, Rothaug O; Albarran J. Family witnessed resuscitation - experience and attitudes of German intensive care nurses. Nurs Crit Care. 2010; 15(5): 241-50. PMid:20712669 http://dx.doi.org/10.1111/j.1478-5153.2010.00405.x

[13] Howlett MS, Alexander GA, Tsuchiya B. Health care providers' attitudes regarding family presence during resuscitation of adults: an integrated review of the literature. Clin Nurse Spec. 2010 May-Jun; 24(3): 161-74. PMid:20404625 http://dx.doi.org/10.1097/NUR.0b013e3181dc548a

[14] Axelsson AB, Fridlund B, Moons P, Martensson J, Op Reimer WS, Smith K, et al. Undertaking Nursing Interventions Throughout Europe (UNITE) study group. European cardiovascular nurses' experiences of and attitudes towards having family members present in the resuscitation room. Eur J Cardiovasc Nurs. 2010; 9(1): 15-23. PMid:19892600 http://dx.doi.org/10.1016/j.ejcnurse.2009.10.001

[15] Zakaria M, Siddique M. Presence of family members during cardio-pulmonary resuscitation after necessary amendments. J Pak Med Assoc. 2008 Nov; 58(11): 632-5. PMid:19024137

[16] Fallis WM, McClement S, Pereira A. Family presence during resuscitation: a survey of Canadian critical care nurses' practices and perceptions. Dynamics. 2008; 19(3): 22-8. PMid:18773712

[17] Walker W. Accident and emergency staff opinion on the effects of family presence during adult resuscitation: critical literature review. Journal of Advanced Nursing. 2007; 61(4): 348-362. PMid:18234033 http://dx.doi.org/10.1111/j.1365-2648.2007.04535.x

[18] Badir A, Sepit D. Family presence during CPR: a study of the experiences and opinions of Turkish critical care nurses. International Journal of Nursing Studies. 2007; 44(1): 83-92. PMid:16426618 http://dx.doi.org/10.1016/j.ijnurstu.2005.11.023

[19] Engel KG, Barnosky AR, Berry-Bovia M, Desmond JS, Ubel PA. Provider Experience and Attitudes toward Family Presence during Resuscitation Procedures. Journal of Palliative Medicine. 2007; 10(5): 1007-1010. PMid:17985951 http://dx.doi.org/10.1089/jpm.2007.0096

[20] Kirchhoff C, Stegmaier J, Buhmann S, Leidel BA, Biberthaler P, Mutschler W, et al. Trauma surgeons' attitude towards family presence during trauma resuscitation: a nationwide survey. Resuscitation. 2007; 75(2): 267-275. PMid:17553609 http://dx.doi.org/10.1016/j.resuscitation.2007.04.015

[21] Whittemore R, Knafl K. The integrative review: updated methodology. Journal of Advanced Nursing. 2005; 52(5): 546-553. PMid:16268861 http://dx.doi.org/10.1111/j.1365-2648.2005.03621.x

[22] Sampieri RH, Collado CF, Lucio PB. Capítulo 10: Análisis de los datos. Metodología de la investigación. [Data analysis. Research methodology]. 2a. ed. México: McGraw-Hill; 1998. p. 579-607. (Spanish).

[23] Demir F. Presence of patients' families during cardiopulmonary resuscitation: physicians' and nurses’ opinions. Journal of Advanced Nursing. 2008; 63(4): 409-416. PMid:18727768 http://dx.doi.org/10.1111/j.1365-2648.2008.04725.x 